\title{
Vertical Distribution of Particulate Matter and its Relationship with Planetary Boundary Layer Structure in Shenyang, Northeast China
}

\author{
Xiaolan $\mathrm{Li}^{1^{*}}$, Yanjun $\mathrm{Ma}^{1^{*}}$, Yangfeng Wang${ }^{1}$, Wei Wei ${ }^{2}$, Yunhai Zhang ${ }^{1}$, Ningwei Liu ${ }^{1}$, Ye Hong ${ }^{1}$ \\ ${ }^{1}$ Institute of Atmospheric Environment, China Meteorological Administration, Shenyang, Liaoning 110166, China \\ ${ }^{2}$ State Key Laboratory of Severe Weather, Chinese Academy of Meteorological Sciences, Beijing 100081, China
}

\begin{abstract}
The impact of the planetary boundary layer (PBL) structure on the vertical distribution of aerosols in Northeast China, which experiences air pollution frequently in autumn and winter, is not well understood. We investigated the characteristics of the vertical distribution of particulate matter $\left(\mathrm{PM}_{1}, \mathrm{PM}_{2.5}\right.$, and $\left.\mathrm{PM}_{10}\right)$ mass concentrations and their relationships with PBL structures in Shenyang, a provincial capital city in Northeast China, using balloon sounding data collected during an intensive observation period in November 2018. Aerosols typically decreased with increases in height and were mostly distributed below $400 \mathrm{~m}$ at night and reached higher altitudes $(\sim 800 \mathrm{~m})$ in the daytime due to convective turbulence. The concentration ratios of $\mathrm{PM}_{1} / \mathrm{PM}_{2.5}$ and $\mathrm{PM}_{2.5} / \mathrm{PM}_{10}$ measured about 0.6 and 0.8 , respectively, below $0.6-1.0 \mathrm{~km}$ during the daytime, and below $0.5 \mathrm{~km}$ at nighttime. On average, stronger atmospheric stability resulted in greater vertical gradients and higher PM concentrations near the surface. During four air pollution episodes (November 1-4, 7-10, 14-15, and 25-27), when atmospheric stability was strong at night, aerosols tended to remain in a shallow stable surface layer $(<300 \mathrm{~m})$ and at the bottom of a residual layer $(250-500 \mathrm{~m})$ due to weak vertical mixing. After sunrise, these aerosols were mixed uniformly in the PBL (the depth increasing from $200 \mathrm{~m}$ to more than $1 \mathrm{~km}$ ), subsequently affecting surface air quality. In addition, strong wind speeds and wind shears caused by nocturnal low-level jets and cold front systems influenced the formation and evolution of air pollution episodes. These processes controlled aerosol transport/dispersion processes and can modify atmospheric stability and PBL height. These results have important implications for understanding the vertical distribution of aerosols, and the crucial roles that PBL structures play in modulating aerosol pollution in Shenyang.
\end{abstract}

Keywords: Vertical distribution; Particulate matter; Planetary boundary layer structure; Air pollution; Northeast China.

\section{INTRODUCTION}

Atmospheric particulate matter (PM) can affect air quality (Fuzzi et al., 2015; Jiang et al., 2015), visibility (Kim et al., 2006; Li et al., 2016), human health (Davidson et al., 2005; Kim et al., 2015; Tang et al., 2017), and the earth's radiation budget (Myhre et al., 2013; Huang et al., 2014), depending on particle size. Fine PM with aerodynamic diameters less than 2.5 and $1 \mu \mathrm{m}\left(\mathrm{PM}_{2.5}\right.$ and $\mathrm{PM}_{1}$, respectively) typically poses greater health risks (Oberdörster et al., 2005; Anderson et al., 2012;) and exhibits higher correlations with visibility than coarse PM ( $\left.\mathrm{PM}_{10}\right)$ (Zhao et al., 2013; Li et al., 2017). Over the past decade, PM pollution has become a serious environmental problem in most urban regions in developing Asian countries, such as China and India (Bhaskar and Mehta,

\footnotetext{
* Corresponding author.

Tel.: (024) 8389-3249

E-mail address: leexl.ouc@163.com (X. Li); mayanjun0917@163.com (Y.Ma)
}

2010; Tiwari et al., 2014; Cheng et al., 2015). Previous studies have investigated the horizontal distribution and temporal variation of surface-level PM concentration and their relationships with meteorological conditions in China (Li et al., 2015; Wang et al., 2015b; Zhang et al., 2015). However, the vertical distribution and evolution of PM concentrations, which directly affect near-surface air quality and radiation transfer in the atmosphere, have been rarely reported, mainly because of a lack of observations.

The common methods of measuring vertical profiles of PM concentration in situ include tower measurement, LiDAR detection, and balloon sounding. The vertical distribution of PM concentrations can be measured continuously by gauges at different altitudes on a tower. For example, Deng et al. (2015) analyzed the evolution of $\mathrm{PM}_{1}, \mathrm{PM}_{2.5}$, and $\mathrm{PM}_{10}$ concentrations at 121 and $454 \mathrm{~m}$ on the Canton tower in Guangzhou, China, from November 2010 to May 2013. They observed more uniform vertical distributions for fine PM than coarse PM and during summer than winter. Chan et al. (2005) investigated the characteristics of vertical profiles of $\mathrm{PM}_{2.5}$ and $\mathrm{PM}_{10}$ in urban Beijing during August 2003 using tower observations at 8, 100, 200, and $325 \mathrm{~m}$. 
They reported that strong temperature inversions near the surface $(<50 \mathrm{~m})$ and more stable conditions aloft enhanced the near-surface accumulation of pollutants. However, tower-measured PM vertical profiles often suffer from poor vertical resolution and limitation of detection height (several hundreds of meters at maximum). Using optical principles, fine-resolution vertical profiles of PM concentrations can be retrieved from aerosol extinction coefficients measured using LiDAR. Nevertheless, LiDAR measurements usually have a blind zone near the surface, on the order of several dozens of meters in height where pollution is most concerned (Li et al., 2019). Balloon sounding can be used monitor PM concentrations using optical- or diffusion charging-based sensors with a high vertical resolution (several meters), and can measure standard meteorological variables simultaneously. Balloon sounding released frequently enough can successfully capture the vertical distribution and evolution of atmospheric PM during haze and fog episodes (Bisht et al., 2016; Zhang et al., 2017; Han et al., 2018).

The vertical distribution and evolution of PM concentrations are affected by the dynamic and thermodynamic structures of the planetary boundary layer (PBL). A great deal of research effort has been made to investigate the mechanisms of air pollution formation associated with PBL structures (Ding et al., 2005; Hu et al., 2014; Tang et al., 2015; 2016; Zhu et al., 2016; Yang et al., 2017; Li et al., 2018a, b; Zhu et al., 2018; Miao et al., 2019; Liu et al., 2019). For example, Sun et al. (2013) investigated the impact of PBL structure on the evolution of tower-measured $\mathrm{PM}_{2.5}$ concentrations at three levels in the near-surface layer in Beijing, during a summer haze event (August 1-16, 2009). Han et al. (2018) analyzed the vertical distribution and evolution of $\mathrm{PM}_{2.5}$ concentrations and their relation to PBL structure during a prolonged haze episode (December 20-25, 2015), over central-eastern China using measurements from a tethered balloon. Wang et al. (2019) studied the PBL vertical structure over Beijing urban area and its effect on LiDAR-derived aerosol extinction coefficient during air pollution episodes from December 1 to 4, 2016. These studies mostly focused on individual air pollution episodes lasting for several days. Regular or long-term characteristics of PM vertical distribution and their associations with PBL structures have rarely been reported.

Northeast China had the second highest surface concentrations of $\mathrm{PM}_{1}, \mathrm{PM}_{2.5}$, and $\mathrm{PM}_{10}$ in China during 2006-2014 (second to the North China Plain) (Wang et al., 2015b). Unlike other regions in China, surface PM concentrations in Northeast China have exhibited an increasing trend over the past several years (Wang et al., $2015 b)$. The characteristics of the vertical distribution of PM and its relationship with PBL structures in this region remain unclear. Only a few studies have examined the vertical distribution of aerosols during several air pollution episodes in Northeast China. Dickerson et al. (2007) investigated the impact of a cyclonic system on the vertical distribution and transport of dust and gaseous pollutants $\left(\mathrm{CO}, \mathrm{SO}_{2}\right.$, and $\left.\mathrm{O}_{3}\right)$ from the PBL to the free troposphere over Northeast China using aircraft observations in April 2005. Ma et al. (2018) analyzed the vertical distribution of aerosol extinction coefficients and derived $\mathrm{PM}_{2.5}$ concentrations using a ground-based LiDAR in Shenyang, Northeast China, during two air pollution episodes from December 2016 to January 2017. However, the impact of PBL structures on aerosol vertical distribution in Northeast China has rarely been studied (Li et al., 2019).

Shenyang, a provincial capital, is one of most populated cities in Northeast China (Fig. 1(a)), with a population of 7.37 million in 2017 (National Bureau of Statistics of China; http://data.stats.gov.cn/search.htm). Air pollution occurs frequently in this city during autumn and winter, mainly due to enhanced local emissions (e.g., coal burning for energy and crop-residue burning) and pollutant transport from adjacent polluted regions such as the North China Plain ( $\mathrm{Li}$ et al., 2018a, b; Ma et al., 2018; Miao et al., 2018; Li et al., 2019). In this study, we examined the impact of PBL structures on the evolution of aerosol vertical distributions in Shenyang, a provincial capital city in Northeast China, on both monthly and episodic time scales. Fine-resolution vertical profiles of $\mathrm{PM}_{1}, \mathrm{PM}_{2.5}$, and $\mathrm{PM}_{10}$ concentrations and meteorological parameters in the PBL were measured using intensive balloon soundings in Shenyang during November 1-31, 2018.

The remainder of this paper is organized as follows. Section 2 introduces the observational sites, data and methods. Section 3 analyzes the characteristics of PM vertical distributions and their relations to PBL structures during the observational period and during four air pollution episodes. Finally, conclusions are drawn in Section 4.

\section{DATA AND METHODS}

\section{Vertical Profiles of PM Concentrations and Meteorological Parameters}

Two observation stations less than $8 \mathrm{~km}$ apart were located in the southern urban region of Shenyang (Fig. 1(b)). At the balloon sounding station (BSS) $\left(123.42^{\circ} \mathrm{E}, 41.68^{\circ} \mathrm{N}\right)$, we measured fine-resolution vertical profiles of $\mathrm{PM}_{1}, \mathrm{PM}_{2.5}$, and $\mathrm{PM}_{10}$ concentrations and some meteorological parameters [including air temperature $\left(T_{\mathrm{a}}\right)$, wind speed $(W S)$, and wind direction $(W D)$ ] during November 1-31, 2018. The radiosonde detection system (Model Chuangzhi Tan Kong-1) was developed by the Institute of Atmospheric Physics of the Chinese Academy of Sciences. Balloons were released eight times a day during the periods November 1-9, 15-16, and 25-30, starting at 02:00 local time (LT) at intervals of $3 \mathrm{~h}$, and at 02:00, 08:00, 14:00, and 20:00 LT on all other days. The ascending velocity of the sounding balloons was about $2.5 \mathrm{~m} \mathrm{~s}^{-1}$, and sounding data were recorded at intervals of $1 \mathrm{~s}$. The detection duration was about $20-30 \mathrm{~min}$, and the detection height usually reached up to $1500-2800 \mathrm{~m}$.

Fine-resolution vertical profiles of PM concentrations were measured using a low-cost laser particle matter sensor (Plantower PMS-5003T, China). A fan in the sensor draws air through a chamber where PM with diameters of between 0.3 and $10 \mu \mathrm{m}$ are detected by a $90^{\circ}$-scattered laser-induced light, with the wavelength estimated at $650 \pm 10 \mathrm{~nm}$ (Kelly et al., 2017). The light-scattering signals are subsequently placed into different PM size bins of $0.3-1 \mu \mathrm{m}, 1-2.5 \mu \mathrm{m}$, 

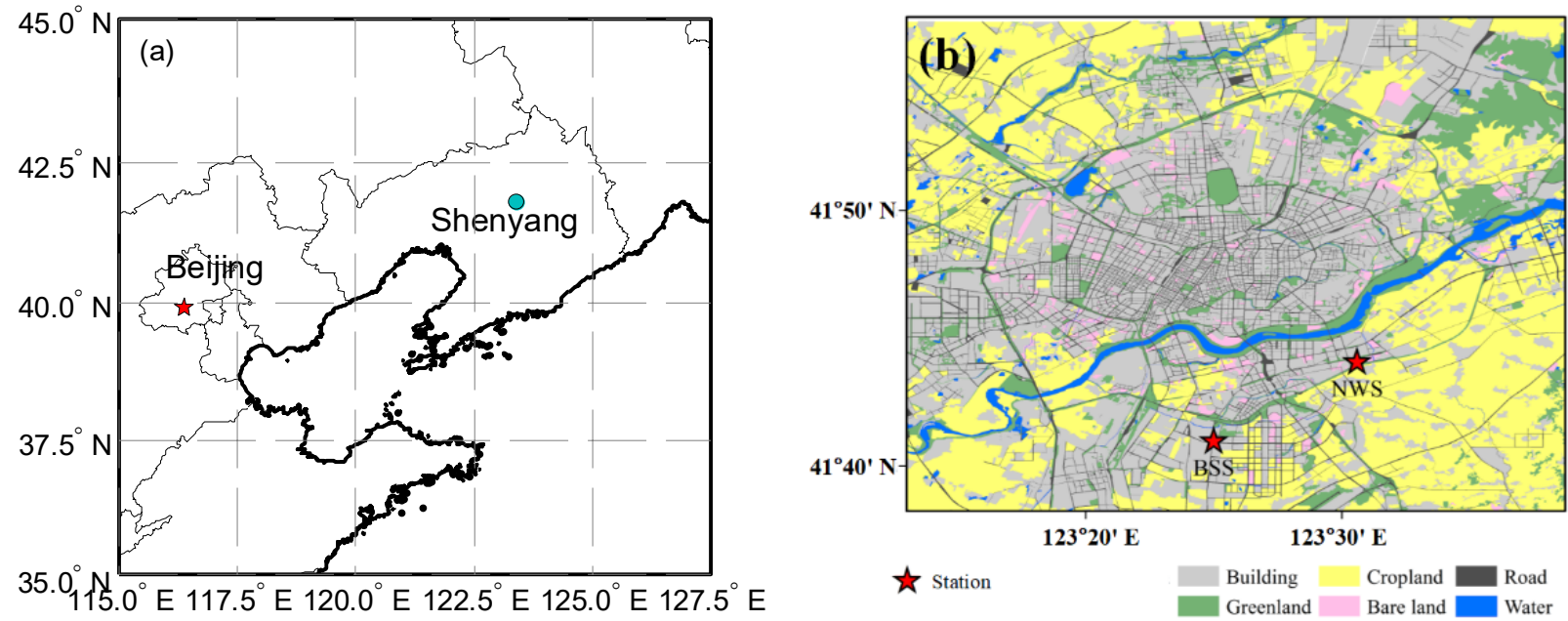

Fig. 1. (a) Geographical location of Shenyang, and (b) the locations of balloon sounding station (BSS) and national weather station (NWS) in Shenyang, with background representing land use type.

and $2.5-10 \mu \mathrm{m}$, and then mass concentrations of $\mathrm{PM}_{1}, \mathrm{PM}_{2.5}$ and $\mathrm{PM}_{10}$ are calculated, with a detection resolution and range of $1 \mu \mathrm{g} \mathrm{m}^{-3}$ and $0-500 \mu \mathrm{g} \mathrm{m}^{-3}$, respectively. The lowcost PM sensors had good performance in field studies, compared to some scientific grade instruments (e.g., TEOM, Thermo Fischer Scientific Inc., USA) (Kelly et al., 2017; Zheng et al., 2018; Bulot et al., 2019; Sayahi et al., 2019). They have been also used for research on air quality and health risk assessment in different regions and countries, such as India, China, and the United States, in recent years (Masic et al., 2017; Sakhnini et al., 2018; Camprodon et al., 2019; Nelson et al., 2019).

In addition, vertical profiles of $T_{\mathrm{a}}, W S$, and $W D$ were simultaneously measured at the BSS, with a detection resolution of $0.1^{\circ} \mathrm{C}, 0.1 \mathrm{~m} \mathrm{~s}^{-1}$, and $0.1^{\circ}$, respectively. All of the radiosonde data (including $\mathrm{PM}$ and meteorology) were averaged every $10 \mathrm{~m}$ in the vertical direction after data quality control. Vertical profiles of potential temperature $(\theta)$ were also calculated to examine variation in atmospheric stability.

The reliability of balloon sounding data was evaluated using the measurements aerosol extinction coefficients from a ground-based LiDAR (located at $41.74^{\circ} \mathrm{N}, 123.43^{\circ} \mathrm{E}$ ) for November 1-3 and conventional meteorological sounding data from a L-band radiosonde system at the national weather station (NWS) (located at $\left.123.51^{\circ} \mathrm{E}, 41.74^{\circ} \mathrm{N}\right)$ in Shenyang at 08:00 and 20:00 Local Time (LT) for each day in November 2018 (see Appendix A). Detailed information on the aerosol LiDAR and the L-band radiosonde system can be found in Li et al. (2019). Evolution of the vertical distribution in $\mathrm{PM}_{2.5}$ concentrations measured using the balloon sounding were basically consistent with that of the aerosol extinction coefficient from November 1 to 3, 2018. Both observed that aerosols increased and were transported at higher altitudes with time during this period, and mostly accumulated at altitudes below $0.5 \mathrm{~km}$ and near $1 \mathrm{~km}$ at night on November 2 (Fig. S1). The vertical distribution of $\theta$ and WS measured at BSS also varied consistently with that observed at NWS during the entire study period (Fig. S2).

\section{Surface PM concentrations and Meteorological Parameters}

The hourly mean mass concentrations of $\mathrm{PM}_{10}$ and $\mathrm{PM}_{2.5}$ near the surface were obtained from 11 national air quality monitoring stations in Shenyang. The averaged PM concentrations from the 11 stations (representing the mean air quality in the city) were used to identify air pollution episodes during the study period, and to evaluate the variation trend of near-surface PM concentrations measured using balloon sounding. The distribution and detailed information of each station were reported previously (Li et al., 2017). To explain the potential long-range transport of air pollutants from the North China Plain to Shenyang, we also selected hourly mean $\mathrm{PM}_{2.5}$ concentrations at another 24 cities (20 cities in North China Plain and 4 in Liaoning province) in November 2018. In addition to surface-level PM monitoring data, surface meteorological observations, including hourly mean $W S, W D, T_{\text {a }}$, relative humidity $(R H)$, and atmospheric visibility (Vis) in November 2018, were obtained from the NWS.

\section{Wind Fields from European Centre for Medium Range Weather Forecasts Reanalysis Data}

Reanalysis data from The European Centre for Medium Range Weather Forecasts (ECMWF) were used to reproduce the horizontal flow fields at $10 \mathrm{~m}$ height over the North China Plain and Liaoning province during two air pollution episodes in November 2018. The horizontal meridional and zonal wind speeds $(u$ and $v)$ were obtained at 02:00, 08:00, 14:00, and 20:00 LT each day, with a spatial resolution of $0.125^{\circ} \times 0.125^{\circ}$.

\section{Determination of Planetary Boundary Layer Height}

Planetary boundary layer height (PBLH) directly determines the vertical dilution range of air pollutants, and thus affects surface air quality. We applied the 1.5- $\theta$-increase method (Nielsen-Gammon et al., 2008) and the critical bulk Richardson number $\left(R_{\mathrm{i}}\right)$ method (Stull, 1988) to determine the PBLH in the daytime and nighttime, respectively, using 
balloon sounding data. The former method defines the PBLH as the altitude where $\theta$ first exceeds the minimum $\theta$-value within the boundary layer by $1.5 \mathrm{~K}$, while the latter determines the PBLH as the lowest altitude where $R_{\mathrm{i}}$ is larger than 0.25 . The two methods have been widely used in previous studies to analyze PBL structures and their effects on air pollution (Hong, 2010; Seidel et al., 2012; Hu et al., 2014; Guo et al., 2016; Li et al., 2018a, 2019; Yang et al., 2019).

\section{Occurrence Frequency of Unstable Conditions}

The occurrence frequency of unstable conditions at different altitudes and hours, $f\left(H_{n}, t\right)$, is calculated according to Eqs. (1) and (2), to quantitatively analyze the diurnal variation in the thermodynamic structure of the PBL.

$\delta \theta(z, t)=\delta(z+1, t)-\theta(z, t)$

$f\left(H_{n}, t\right)=\frac{\operatorname{Num}\left(\delta \theta\left(H_{n}<z<H_{n+1}, t\right)<0\right)}{\operatorname{Num}\left(\delta \theta\left(H_{n}<z<H_{n+1}, t\right)\right)}$

We calculated the difference in $\theta$ at two adjacent altitudes for different hours, $\delta \theta(z, t)$, with $z$ and $t$ being observational height and time, respectively. If $\delta \theta(z, t)<0$, this represents unstable conditions at the given height and time. Thereafter, we counted the number of times unstable conditions occurred within each $100 \mathrm{~m}$ vertical range at different hours (the numerator in Eq. (2), with $H_{\mathrm{n}}=0,100,200, \ldots, 1600 \mathrm{~m}$ ), and found the proportion of this frequency in relation to the total sample number at the same heights and hours. Finally, the mean diurnal variation of $f\left(H_{n}, t\right)$ was calculated for November 2018.

\section{RESULTS}

\section{Vertical Distribution of PM Concentrations and}

Meteorological Parameters during November 2018

Fig. 2 shows the evolution and vertical distributions of $\mathrm{PM}_{1}$, $\mathrm{PM}_{2.5}$, and $\mathrm{PM}_{10}$ concentrations below $2 \mathrm{~km}$ and the temporal variation of hourly mean surface-level $\mathrm{PM}_{2.5}$ and $\mathrm{PM}_{10}$ concentrations in Shenyang during November 2018. Overall, the vertical distributions of $\mathrm{PM}_{1}, \mathrm{PM}_{2.5}$, and $\mathrm{PM}_{10}$ concentrations showed similar evolution to each other and had consistent trends with the surface-level $\mathrm{PM}_{2.5}$ and $\mathrm{PM}_{10}$ concentrations during the observation period. An aerosol-rich layer persisted below $0.3-0.6 \mathrm{~km}$ and sometimes extended up to $1.5-2 \mathrm{~km}$ and even higher altitudes during the study period except on November 16 when a cold front system passed over Shenyang. PM concentrations typically decreased with an increase in height, mainly due to enhanced emissions near the surface, and dry deposition of aerosols. This is consistent with long-term tower observations from other cities, such as Guangzhou (Deng et al., 2015), and episodic measurements using aerial vehicles in the Yangtze River Delta (Wang et al., 2015a; Lu et al., 2019) in China. The inverse was also observed at times, where PM concentrations increased with height, particularly during some pollution episodes. This is discussed in Section 3.4.

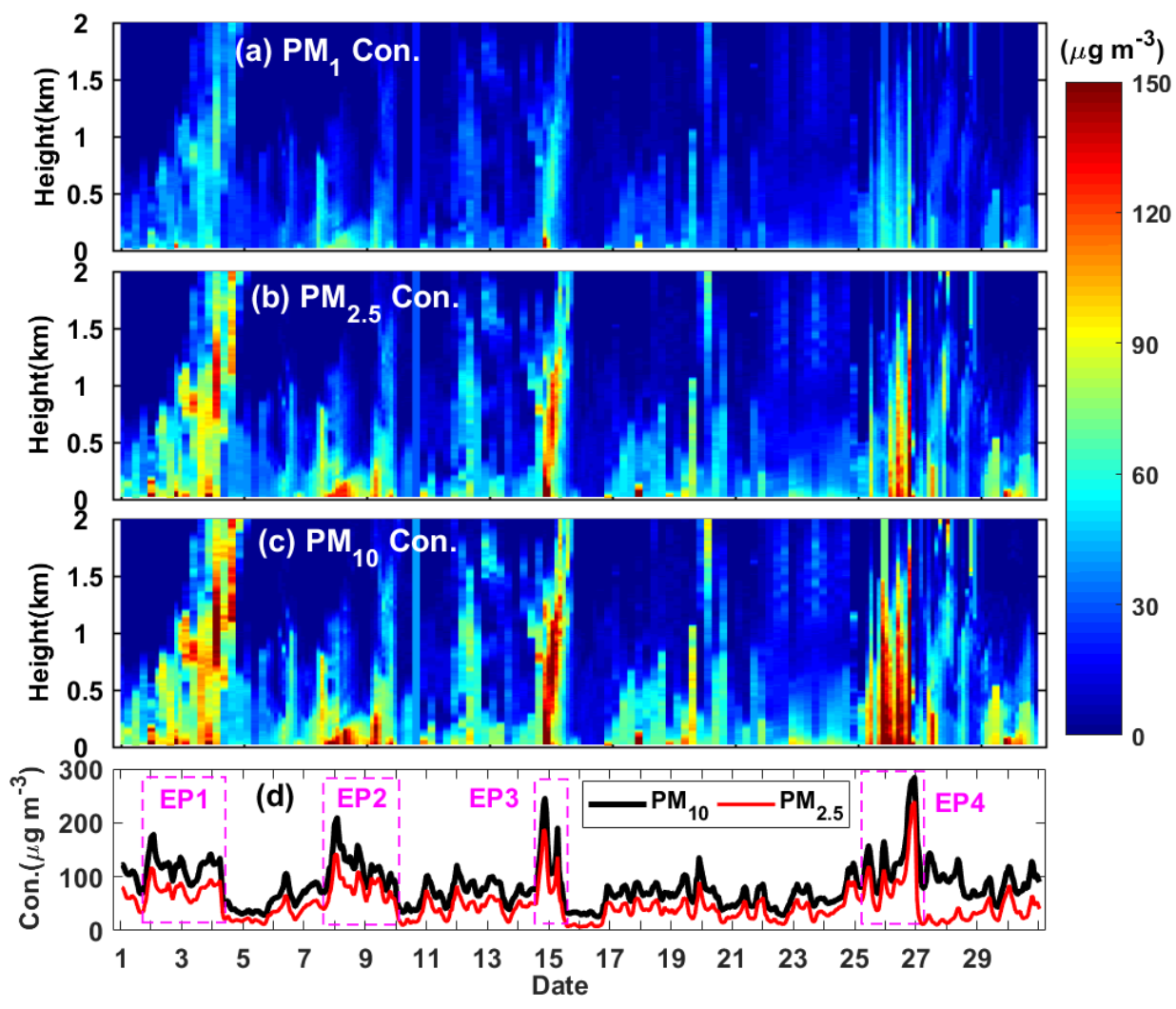

Fig. 2. Height-time cross-sections of mass concentrations of (a) $\mathrm{PM}_{1}$, (b) $\mathrm{PM}_{2.5}$, and (c) $\mathrm{PM}_{10}$, and (d) variation of surface $\mathrm{PM}_{2.5}$ and $\mathrm{PM}_{10}$ concentrations in Shenyang during November 2018. Rectangles represent air pollution episodes. 
Four air pollution episodes, characterized by the maximum hourly mean surface $\mathrm{PM}_{2.5}$ and $\mathrm{PM}_{10}$ concentrations greater than 100 and $150 \mu \mathrm{g} \mathrm{m}^{-3}$, respectively, were distinguished in November 2018 in Shenyang. The first pollution episode (EP1) occurred from 16:00 LT on November 1 to 07:00 LT on November 4, EP2 occurred from 15:00 LT on November 7 to 01:00 LT on November 10, EP3 occurred from 11:00 LT on November 14 to 12:00 LT on November 15, and EP4 occurred from 02:00 LT on November 25 to 02:00 LT on November 27, 2018. During the four air pollution episodes, the maximum surface-level hourly mean $\mathrm{PM}_{2.5}\left(\mathrm{PM}_{10}\right)$ concentrations reached 117 (178), 142 (209), 187 (245), and $240(284) \mu \mathrm{g} \mathrm{m}^{-3}$, respectively, and near-surface PM concentrations measured using balloon sounding also increased significantly.

To understand the evolution of PBL structure and surface meteorological conditions during the study period, Fig. 3 shows the vertical distributions of $\theta$ and $W S$ below $2 \mathrm{~km}$ and variation of hourly mean $T_{\mathrm{a}}, R H, W S, W D$, and visibility at a height of $2 \mathrm{~m}$ during November 2018 in Shenyang. The variation of surface $T_{\mathrm{a}}$ and $W S$ measured at the NWS was consistent with that of $\theta$ and WS measured using balloon sounding. Regular diurnal variation of $\theta, T_{\mathrm{a}}$, and $R H$ was observed on most days in this month, with higher temperature and lower $R H$ in the daytime. Potential temperature inversions usually occurred at night due to the infrared radiative cooling of the surface. During all air pollution episodes, low visibility $(<2 \mathrm{~km})$, high $R H(>80 \%)$, and frequent changes in $W D$ were observed near the surface. However, WS exhibited large differences among different episodes. Strong winds near the surface $\left(W S>6 \mathrm{~m} \mathrm{~s}^{-1}\right)$ and at higher altitudes $\left(W S>15 \mathrm{~m} \mathrm{~s}^{-1}\right)$ were observed during EP1 and EP4, indicating that both episodes were probably related to the transport of air pollutants, while weak winds dominated in EP2 and EP3.

\section{Diurnal Variation of Vertical Distribution of PM Concentration}

The mean diurnal variation of the vertical profiles of $\mathrm{PM}_{1}$, $\mathrm{PM}_{2.5}$, and $\mathrm{PM}_{10}$ concentrations within $1.5 \mathrm{~km}$ above the surface in November 2018 in Shenyang are shown in Fig. 4. On average, PM concentrations decreased with height at all hours. At night (02:00, 05:00, 20:00, and 23:00 LT), PM concentrations decreased rapidly with height below $500 \mathrm{~m}$, with average lapse rates of 5.8, 9.7, and $11.7 \mu \mathrm{g} \mathrm{m}^{-3} / 100 \mathrm{~m}$ for $\mathrm{PM}_{1}, \mathrm{PM}_{2.5}$, and $\mathrm{PM}_{10}$, respectively, and changed slowly aloft. In the daytime (08:00-17:00 LT), PM concentrations were distributed more uniformly in the vertical direction; the smallest concentration lapse rates of about 1.8, 3.0, and $3.8 \mu \mathrm{g} \mathrm{m}^{-3} / 100 \mathrm{~m}$ below $500 \mathrm{~m}$ were observed at 14:00 LT for $\mathrm{PM}_{1}, \mathrm{PM}_{2.5}$, and $\mathrm{PM}_{10}$, respectively. Aerosols were mostly distributed below $400 \mathrm{~m}$ at night, but were transported to higher altitudes (up to $\sim 800 \mathrm{~m}$ ) during the daytime due to strong convective turbulence.

Using aerial vehicle observations, Lu et al. (2019) also observed that the vertical gradient of $\mathrm{PM}_{2.5}$ concentrations decreased from the morning to the afternoon due to the diurnal variation of the PBL structure, on 5 days between August 2014 and February 2015 in a suburban area in Lin'an, China $\left(29^{\circ} 56^{\prime}-30^{\circ} 23^{\prime} \mathrm{N}, 118^{\circ} 51^{\prime}-11^{\circ} 52^{\prime} \mathrm{E}\right)$. Due to the enhanced turbulence between 13:00 and 18:00 LT, the

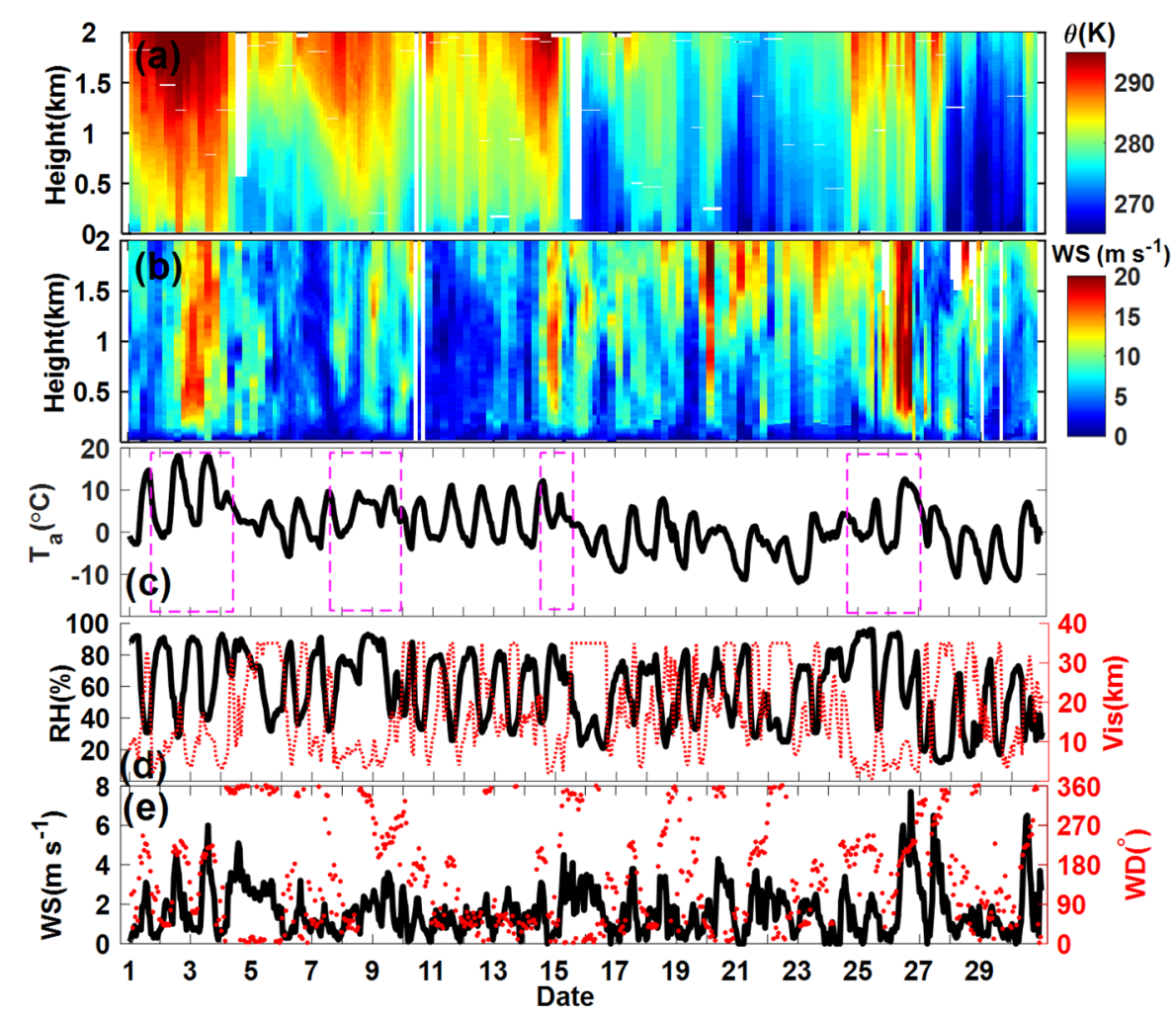

Fig. 3. Vertical distributions of (a) potential temperature and (b) wind speed, and temporal variation of (c) air temperature, (d) relative humidity, and (e) wind speed and direction at $2 \mathrm{~m}$ height, observed in Shenyang during November 2018. 


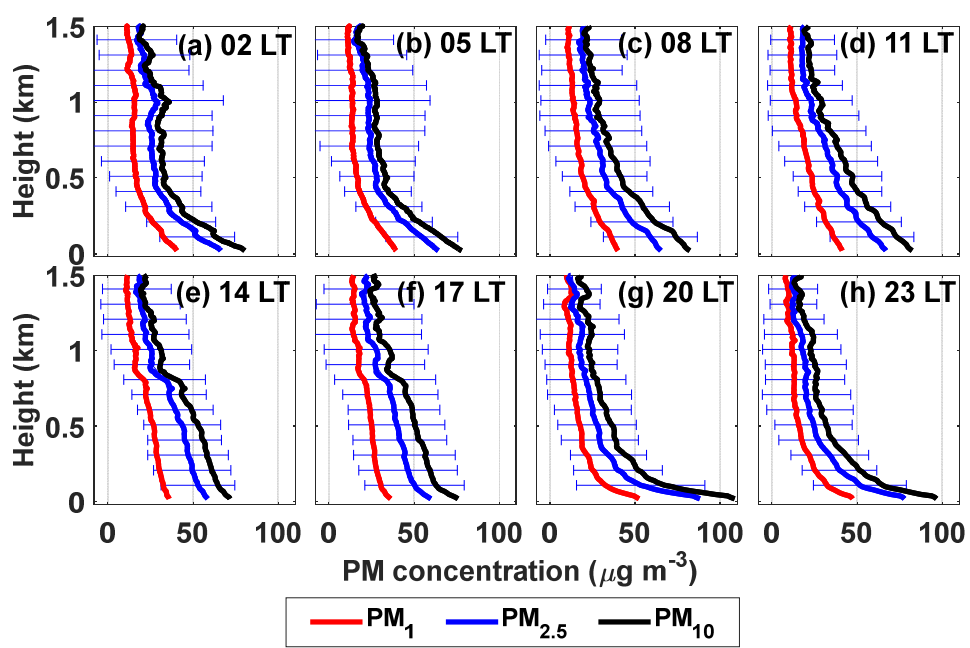

Fig. 4. Monthly averaged vertical profiles of $\mathrm{PM}_{1}, \mathrm{PM}_{2.5}$, and $\mathrm{PM}_{10}$ concentrations at (a) 02:00, (b) 05:00, (c) 08:00, (d) 11:00, (e) 14:00, (f) 17:00, (g) 20:00, and (h) 23:00 LT, observed at Shenyang in November 2018. The blue bar represents the standard deviation of $\mathrm{PM}_{2.5}$ concentrations.

ratios of $\mathrm{PM}_{10}$ concentration at heights of 100 and $320 \mathrm{~m}$ to those at $8 \mathrm{~m}$ increased by $5 \%$ and $13 \%$, respectively, compared to the daily mean ratios, and the mean ratio of $\mathrm{PM}_{2.5}$ between 100 and $8 \mathrm{~m}$ heights even ranged from $101 \%$ to $120 \%$, according to tower observations in Beijing in August 2003 (Ding et al., 2005).

On average, higher PM concentrations were observed near the surface at night than during the daytime, partly due to diurnal variation of the PBL structure. Similar diurnal variation was also observed in the surface-level PM concentrations at air quality monitoring stations in Shenyang during this study period (not shown) and in different seasons in 2014 and 2015 (Li et al., 2016).

To examine the proportions of airborne fine and coarse particles at different levels, Fig. 5 shows the mean vertical distributions of concentration ratios of $\mathrm{PM}_{1} / \mathrm{PM}_{2.5}, \mathrm{PM}_{2.5} / \mathrm{PM}_{10}$, and $\mathrm{PM}_{1} / \mathrm{PM}_{10}$ at different hours averaged in November 2018 in Shenyang. Fine particles accounted for a large proportion of aerosols at all altitudes; the monthly averaged ratios of $\mathrm{PM}_{1} / \mathrm{PM}_{2.5}$ and $\mathrm{PM}_{2.5} / \mathrm{PM}_{10}$ below $1.5 \mathrm{~km}$ ranged from 0.53 to 0.96 and from 0.65 to 1 , respectively. The ratios of $\mathrm{PM}_{1} / \mathrm{PM}_{2.5}$ and $\mathrm{PM}_{2.5} / \mathrm{PM}_{10}$ remained about 0.6 and 0.8 below $0.5 \mathrm{~km}$ at night and below $0.6-1.0 \mathrm{~km}$ in the daytime, and aloft they exhibited larger fluctuations and an increasing trend with height. The $\mathrm{PM}_{2.5} / \mathrm{PM}_{10}$ ratio approached one at altitudes of $1.3-1.5 \mathrm{~km}$, which was mainly because coarse particles typically show stronger dry deposition than fine particles. The annual mean ratios of surface-level $\mathrm{PM}_{2.5} / \mathrm{PM}_{10}$ in Shenyang from 2010 to 2012 ranged from 0.69 to 0.73 (Zhao et al., 2013), and their monthly mean ratios ranged between 0.50 and 0.81 from 2014 to 2015 (Li et al., 2016). These values are close to the near-surface ratios observed in this study.

\section{Impact of PBL Structure on Diurnal Variation of PM Vertical Distribution}

The diurnal variation of PM vertical distributions is closely related to the diurnal evolution of PBL structures. As shown in Fig. 6, the vertical profiles of $\theta$ at night averaged in November 2018 exhibited stronger atmospheric stability than those in the daytime. Between 20:00 and 05:00 LT, the $\theta$-difference from the surface to $200 \mathrm{~m}$ height increased from 0.14 to $0.26 \mathrm{~K}$, due to continuous radiative cooling of the surface after sunset. Stronger atmospheric stability suppressed vertical mixing of aerosols and trapped more aerosols near the surface. During the daytime, atmospheric stability became weak because of solar heating of the surface; a small vertical gradient of $\theta$ was observed below $0.3 \mathrm{~km}$ at 08:00 LT and below $1 \mathrm{~km}$ at 14:00-17:00 LT on average. Strong convective unstable conditions favored vertical transport of aerosols and resulted in a more uniform vertical distribution of PM concentrations.

To show the diurnal evolution of atmospheric stability more clearly, the diurnal mean occurrence frequency of unstable conditions at different altitudes, averaged for November 2018 is displayed in Fig. 7. Unstable conditions occurred more frequently during 08:00-17:00 LT than during other times, with the highest frequency observed at 14:00 LT. Unstable conditions occurred frequently $(>35 \%)$ below $0.1 \mathrm{~km}$ at 08:00 LT, and extended up to more than $1 \mathrm{~km}$ at 14:00 LT, which reflected the growth of the PBLH and corresponded to the vertical mixing range of aerosols. Unstable conditions also occurred at night at altitudes between $0.5-1 \mathrm{~km}$ altitudes, with the highest frequency being larger than $30 \%$, probably caused by low-level jets (LLJs). LLJs often occur within the boundary layer and are characterized by a pronounced diurnal cycle in winds with the maximum occurring at night (Du et al., 2014a). As shown in Fig. 6, stronger wind speed and wind shear were observed in the PBL at night, with the maximum mean $W S$ close to $8 \mathrm{~m} \mathrm{~s}^{-1}$ at altitudes of 400-600 m. Previous studies have shown that LLJs affect the transport and dispersion of air pollutants in the PBL (Hu et al., 2013a, b; Klein et al., 2014; Wei et al., 2018; Miao et al., 2019; Wang et al., 2019). LLJs occur more frequently in Northeast China than most other regions in China (Du et al., 2014b), potentially modifying the vertical distribution of aerosols in Shenyang. 


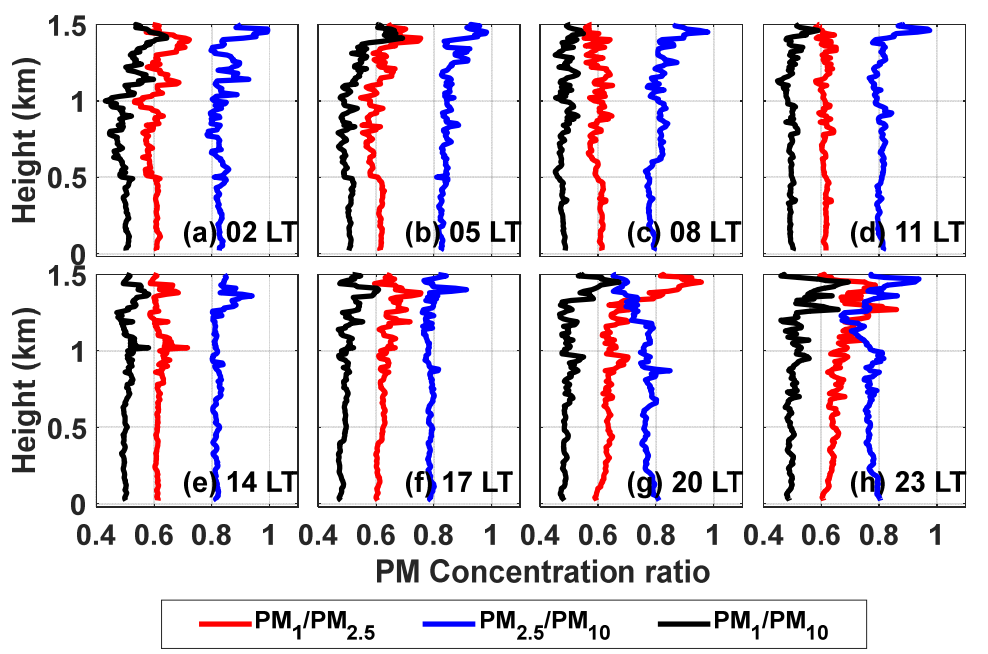

Fig. 5. Monthly averaged vertical profiles of $\mathrm{PM}_{1} / \mathrm{PM}_{2.5}, \mathrm{PM}_{2.5} / \mathrm{PM}_{10}$, and $\mathrm{PM}_{1} / \mathrm{PM}_{10}$ ratio at (a) 02:00, (b) 05:00, (c) 08:00, (d) 11:00, (e) 14:00, (f) 17:00, (g) 20:00, and (h) 23:00 LT observed at Shenyang in November 2018.

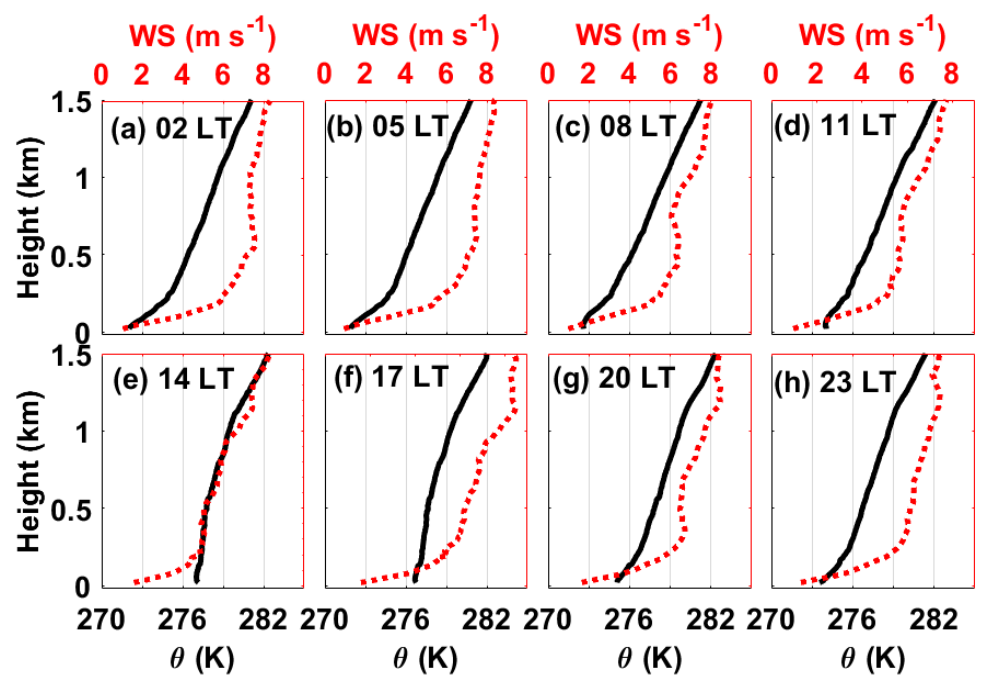

Fig. 6. Vertical profiles of potential temperature and wind speed at (a) 02:00, (b) 05:00, (c) 08:00, (d) 11:00, (e) 14:00, (f) 17:00, (g) 20:00, and (h) 23:00 LT observed at Shenyang averaged over November 2018.

To further quantify the impact of atmospheric stability on the vertical distribution of PM concentrations, the relationship between vertical gradient of PM concentration and $\theta$ between $200 \mathrm{~m}$ and the surface are shown in Fig. 8. The vertical gradient of PM concentrations increased with increasing atmosphere stability (represented by the difference between $\theta$ at the surface and at $200 \mathrm{~m}$ ). When the vertical gradient of $\theta$ between $200 \mathrm{~m}$ and the surface increased by $1 \mathrm{~K}$, the differences of $\mathrm{PM}_{1}, \mathrm{PM}_{2.5}$, and $\mathrm{PM}_{10}$ concentrations at the two levels increased by about $4.9,8.9$, and $10.5 \mu \mathrm{g} \mathrm{m}^{-3}$, respectively. Thus, the increase in atmospheric stability favored the trapping of more pollutants in the near-surface layer, and resulted in deterioration of air quality near the surface at night.

\section{Impact of PBL Structure on Vertical Distribution of PM Concentrations during Air Pollution Episodes}

The impacts of PBL structures on the vertical distribution of PM concentrations were further examined during the four air pollution episodes, to help understand the formation and mechanisms of air pollution in this region. Fig. 9 shows the vertical profiles of $\mathrm{PM}_{2.5}$ concentration, $W S$, and $\theta$ during EP1 and EP4; both episodes were likely related to the long-range transport of pollutants. During EP1, the near-surface $\mathrm{PM}_{2.5}$ concentration was greater than $200 \mu \mathrm{g} \mathrm{m}^{-3}$ and decreased sharply with height at 20:00 LT on November 2 . The strong potential temperature inversion layer and low wind speed near the surface favored the accumulation of pollutants in the shallow stable surface layer. Subsequently, nocturnal LLJs developed during the period from 20:00 LT on November 2 to 08:00 LT on November 3. Here, we identified LLJs following the method in Du et al. (2014b) using two criteria: (1) the maximum WS is more than $10 \mathrm{~m} \mathrm{~s}^{-1}$ below $4 \mathrm{~km}$ (occurring below $1 \mathrm{~km}$ as boundary layer jets and between 1 and $4 \mathrm{~km}$ as synoptic-system-related LLJs); and (2) the WS must decrease by at least $3 \mathrm{~m} \mathrm{~s}^{-1}$ between the 


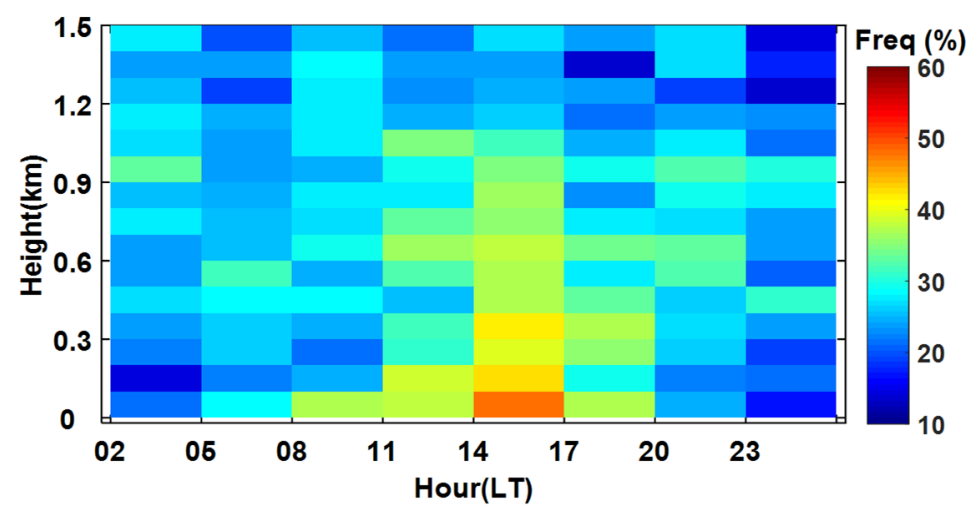

Fig. 7. Mean diurnal variation of vertical distribution of occurrence frequency of unstable conditions for November 2018 in Shenyang.

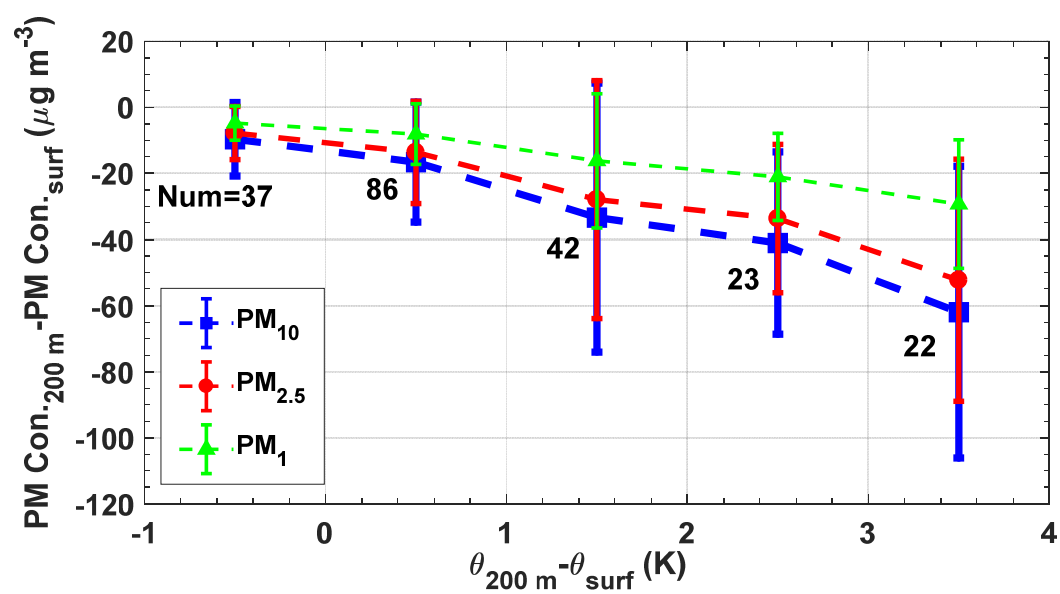

Fig. 8. Relationship between vertical gradient of PM concentrations and potential temperature during November 2018 in Shenyang. The bar represents the standard deviation of PM concentration differences of all samples in each bin.

height of the maximum and minimum wind speed, the minimum being aloft. As shown in Fig. 9(b), the jet core occurred at altitudes between 0.4 and $0.6 \mathrm{~km}$ and the maximum WS reached $16-18 \mathrm{~m} \mathrm{~s}^{-1}$, identifying these as boundary layer jets. With enhancement of boundary layer jets, aerosols were transported from the upstream regions to Shenyang (Fig. 10(a)), and then trapped in a residual layer at nighttime. As a result, $\mathrm{PM}_{2.5}$ concentrations between 0.7 and $1.2 \mathrm{~km}$ heights increased significantly during 23:00 LT on November 2 and 08:00 LT on November 3. After sunrise, WS in the PBL decreased and a deep convective boundary layer (CBL) developed, with the top of the CBL reaching about $1.1 \mathrm{~km}$ at 14:00 LT on November 3. Note that EP1 experienced the warmest weather $\left(20^{\circ} \mathrm{C}\right.$ near the surface) during November 2018 (Fig. 3(c)), which favored the development of CBL. Meanwhile, the pollutants trapped in the residual layer on the previous night were vertically mixed in the CBL due to strong convective turbulence, which led to a uniform vertical distribution of $\mathrm{PM}_{2.5}$ concentration below $1.1 \mathrm{~km}$ and an increase of near-surface $\mathrm{PM}_{2.5}$ concentration. Similar processes were also reported in other air pollution episodes in different regions, such as $\mathrm{O}_{3}$ pollution over the southern Great Plains of the USA (Klein et al., 2014) and over the Yangtze River Delta (Hu et al., 2018), and $\mathrm{PM}_{2.5}$ pollution in Beijing (Sun et al., 2013) and in Northeast China (Li et al., 2019).

During EP4, Shenyang was located ahead of a cold front system (not shown). WS in the PBL increased from 10 to $25 \mathrm{~m} \mathrm{~s}^{-1}$ during 02:00-17:00 LT on November 26 (Fig. 9(e)), which can be identified as the synoptic-system-related LLJs, and the surface hourly mean WS increased from near zero to $8 \mathrm{~m} \mathrm{~s}^{-1}$ (Fig. 3(e)) due to large gradients of surface air pressure. The strong southwesterly winds transported large amounts of pollutants from the North China Plain to Shenyang (Fig. 10(b)), leading to a continuous increase in $\mathrm{PM}_{2.5}$ concentration in the PBL. Meanwhile, strong wind shear weakened atmospheric stability and favored the growth of the PBLH and the vertical mixing of pollutants in the PBL. The PBLH ranged from 1.0 to $1.3 \mathrm{~km}$ during the daytime (Figs. 9(e)-9(f)). At 20:00 LT on November 26, WS in the PBL decreased, but a nocturnal boundary layer jet, with a jet core at an altitude of about $250 \mathrm{~m}$, was observed. Meanwhile, a stable boundary layer with a depth of $250 \mathrm{~m}$ decoupled from a residual layer above it. This PBL structure greatly determined the vertical distribution of $\mathrm{PM}_{2.5}$ concentrations. In the stable surface layer $(<250 \mathrm{~m}), \mathrm{PM}_{2.5}$ concentration remained high at the surface and decreased rapidly with height. Influenced by LLJs, $\mathrm{PM}_{2.5}$ concentration was small and uniformly distributed between 250 and $400 \mathrm{~m}$. Aerosols 

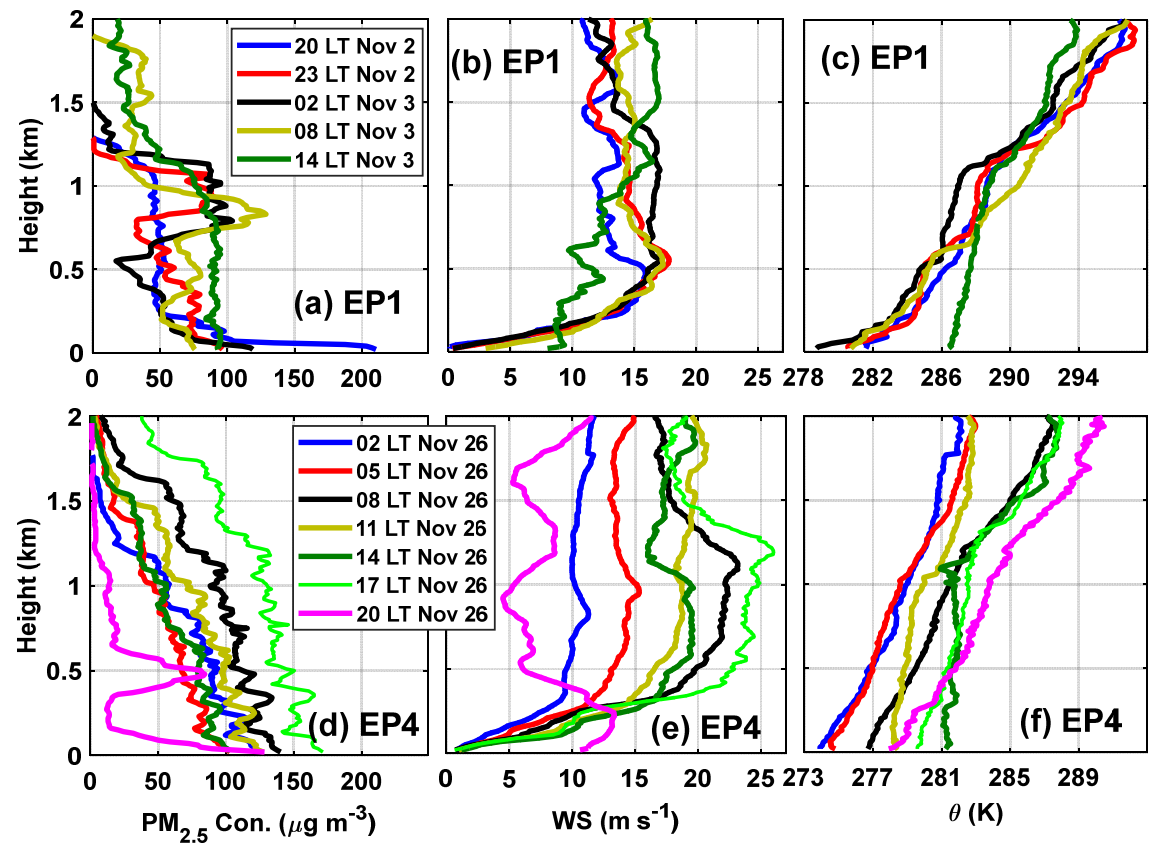

Fig. 9. Vertical profiles of (a, d) $\mathrm{PM}_{2.5}$ concentration, (b, e) wind speed, and (c, f) potential temperature in Shenyang during EP1 on November 2-3 and during EP4 on November 26, 2018.

(a) 0800LT on Nov 3

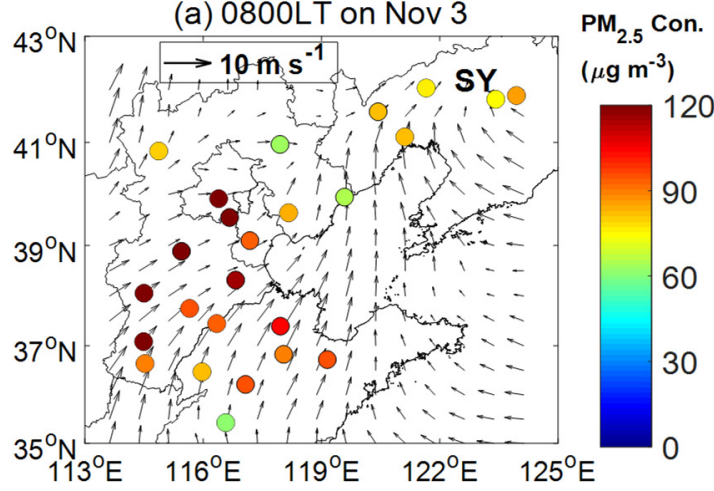

(b) $1400 \mathrm{LT}$ on Nov 26

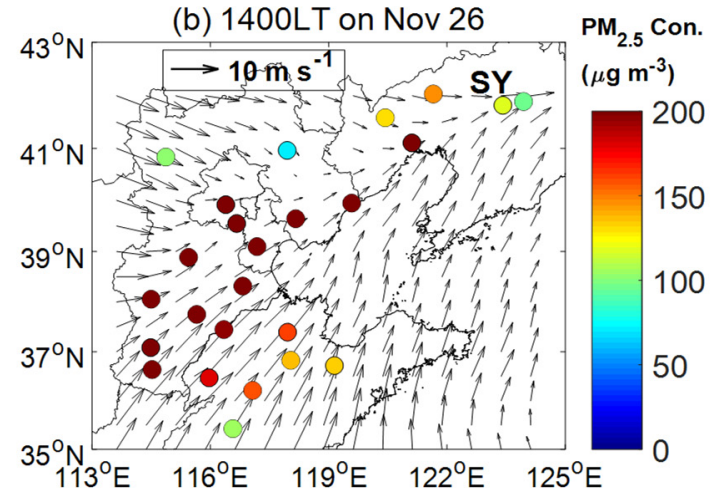

Fig. 10. Wind fields at $10 \mathrm{~m}$ height retrieved from the ECMWF reanalysis data over the North China Plain and Liaoning

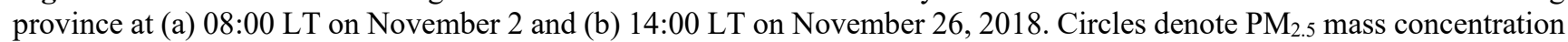
at different cities averaged (a) from 00:00 LT on November 2 to 12:00 LT on November 3 during EP1, and (b) on November 26 during EP4. SY represents the locations of Shenyang.

that cannot be transported/deposited to the surface accumulated at the bottom (400-600 $\mathrm{m}$ ) of the residual layer due to the stable conditions and weak WS, while at higher altitudes PM concentration decreased gradually with height.

The $10 \mathrm{~m}$ winds retrieved from ECMWF reanalysis data at 08:00 LT on 3 November 2018 (EP1) and 14:00 LT on 26 November 2018 (EP4) are overlaid by $\mathrm{PM}_{2.5}$ concentrations averaged for episodic events at 25 cities in the North China Pain and Liaoning province, in Fig. 10. The long-range transport of aerosols during these episodes can be clearly observed. The episodic-mean $\mathrm{PM}_{2.5}$ concentrations exceeded 100 and $200 \mu \mathrm{g} \mathrm{m}^{-3}$ during EP1 and EP4, respectively, for most cities in the North China Plain. These values were much higher than those observed in Liaoning province, including Shenyang. Strong southwesterly and southerly flows dominated the North China Plain and Liaoning province in both pollution episodes, giving favorable conditions for the transport of air pollutants to Shenyang.

In contrast to EP1 and EP4, both EP2 and EP3 were mainly related to local emissions in the presence of weak winds. During EP2, a deep CBL in the daytime gradually turned into a shallow stable surface layer at night (Fig. 11(c)). The PBL height decreased from $0.8 \mathrm{~km}$ to below $0.3 \mathrm{~km}$ from 14:00 LT on November 7 to $02: 00$ LT on November 8, while WS in the PBL increased gradually with time. Correspondingly, $\mathrm{PM}_{2.5}$ concentration $\left(\sim 90 \mu \mathrm{g} \mathrm{m}^{-3}\right)$ was distributed uniformly in the $\mathrm{CBL}$ in the daytime, while at night the near-surface PM concentrations increased gradually because of the strong potential temperature inversion and stagnant WS near the surface. Another PM concentration peak was observed 

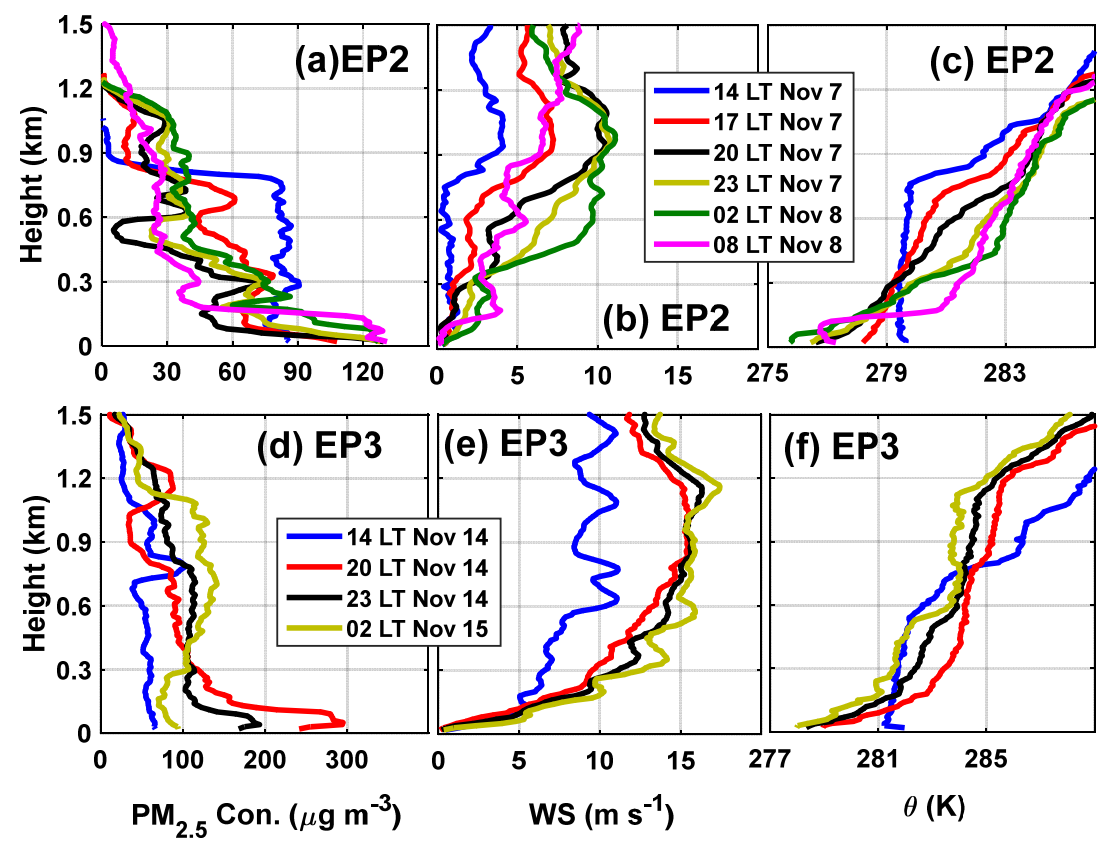

Fig. 11. Vertical profiles of (a, d) $\mathrm{PM}_{2.5}$ concentration, (b, e) wind speed, and (c, f) potential temperature in Shenyang during EP2 on November 7-8 and during EP3 on November 14-15, 2018

in the residual layer at night at altitudes of about $250-350 \mathrm{~m}$ due to strong atmospheric stability. At 08:00 LT on November 8 after sunrise when the convective boundary layer began to develop due to heating of the surface (according to the vertical profile of $\theta), \mathrm{PM}_{2.5}$ concentration was mixed uniformly in the shallow unstable layer below $150 \mathrm{~m}$. Above this altitude, $\mathrm{PM}_{2.5}$ concentration decreased rapidly from 120 to $40 \mu \mathrm{g} \mathrm{m}^{-3}$ because the vertical transport of aerosols was effectively hindered by the $\theta$-inversion layer capped on the CBL. During EP3, the decrease of PBLH and strong stable $\theta$-inversion layer caused an increase of $\mathrm{PM}_{2.5}$ concentration near the surface. With the enhancement of nocturnal LLJs, the aerosols between 0.3 to $1.2 \mathrm{~km}$ also increased at 02:00 LT on November 15 . During the four air pollution episodes, the vertical distribution of PM concentration/surface air quality was closely related to the thermodynamic (related to atmospheric stability) and dynamic structures (largely influenced by LLJs) of the PBL.

\section{CONCLUSIONS AND DISCUSSIONS}

Using intensively collected radiosonde data of $\mathrm{PM}_{1}$ $\mathrm{PM}_{2.5}$, and $\mathrm{PM}_{10}$ concentrations and meteorological parameters in Shenyang during November 2018, we investigated the characteristics of aerosol vertical distributions, and the impact of PBL structures on their mean diurnal variation, and during four air pollution episodes. The main conclusions can be summarized as follows.

(1) Diurnal variation in the PBL structures affect the mean diurnal evolution of vertical distribution of PM concentrations. On average, aerosols were distributed in a shallower layer $(<400 \mathrm{~m})$, and had higher near-surface concentrations and greater decreasing rate with an increase in height, due to stronger atmospheric stability at night, compared to the daytime.
(2) The impact of the thermodynamic structure of the PBL on the vertical distribution of aerosols was clearly demonstrated during four air pollution episodes. PM tended to be trapped in a shallow stable surface layer (usually $<300 \mathrm{~m}$ ) and in the lower part of a residual layer $(250-500 \mathrm{~m})$ when atmospheric stability was strong at night; stable stratification effectively suppressed the vertical mixing of aerosols. During the daytime, aerosol particles were mixed uniformly in the PBL (with gradually increasing height up to approximately $1 \mathrm{~km}$ ) due to enhanced convective turbulence, which subsequently influenced the surface air quality.

(3) The PBL dynamic structure, dominantly affected by LLJs (both boundary layer jets and synoptic-system-related LLJs) in EP1 and EP4, strongly influenced aerosol transport and dispersion processes and modified the atmospheric stability and PBLH, therefore influencing the formation of air pollution. Strong southwesterly and southerly flows caused by LLJs transported amount of pollutants from the North China Plain to Shenyang during EP1 and EP4. Weak winds in EP2 and EP3 favored the accumulation of pollutants from local emissions.

(4) Previous studies of LLJs in Northeast China have focused on their impact on precipitation in summer (Du et $a l ., 2014 \mathrm{~b}$ ), but their impact on the formation and distribution of air pollution in this region has rarely been reported ( $\mathrm{Li}$ et $a l ., 2019)$. It is necessary to investigate the characteristics (such as occurrence frequency and intensity) of LLJs in Northeast China during autumn and winter, and explore their relation to the formation of air pollution. This will likely be beneficial for improving the early warning and forecasting of air pollution episodes.

(5) Long-term and multi-site observations are needed to provide a full understanding of the characteristics of aerosol vertical distribution, and the formation and evolution of air 
pollution in Northeast China. Comparative studies at different sites in urban, suburban, and rural areas will help clarify the effects of anthropogenic activities (including anthropogenic emissions, urban heat island effects, and so forth) on aerosol vertical distributions and air pollution.

\section{ACKNOWLEDGEMENT}

This work was supported by the National Key R\&D Program of China (No. 2017YFC0212301, 2016YFC0203304), National Natural Science Foundation of China (41730647, 41875157, 41605112), Key Program of Science Foundation of Liaoning Meteorological Office (201904), Basic Research Funds of Central Public Welfare Research Institutes (2018SYIAEZD4), and Key Program of Natural Science Foundation of Liaoning Province (20170520359). The authors would like to acknowledge the China Meteorological Administration for providing the meteorological observations (http://data.cma.cn/).

\section{REFERENCE}

Anderson, J.O., Thundiyil, J.G. and Stolbach, A. (2012). Clearing the air: A review of the effects of particulate matter air pollution on human health. J. Med. Toxicol. 8: 166-175. doi: 10.1007/s13181-011-0203-1

Bhaskar, B.V. and Mehta, V.M. (2010). Atmospheric particulate pollutants and their relationship with meteorology in Ahmedabad. Aerosol Air Qual. Res. 10: 301-315. doi: 10.4209/aaqr.2009.10.0069

Bisht, D.S., Tiwari, S., Rao, P.S.P., Ali, K., Prabhakaran, T., Panickar, A.S., Soni, V.K., Attri, S.D., Tunved, P., Chakrabarty, R.K. and Hopke, P.K. (2016). Tethered balloon-born and ground-based measurements of black carbon and particulate profiles within the lower troposphere during the foggy period in Delhi, India. Sci. Total Environ. 573: 894-905.

Bulot, F.M., Johnston, S.J., Basford, P.J., Easton, N.H., Apetroaie-Cristea, M., Foster, G.L., Morris, A.K., Cox, S.J. and Loxham, M. (2019). Long-term field comparison of multiple low-cost particulate matter sensors in an outdoor urban environment. Sci. Rep. 9: 7497. doi: 10.1038/s41598-019-43716-3

Camprodon, G., González, Ó., Barberán, V., Pérez, M., Smári, V., de Heras, M.Á. and Bizzotto, A. (2019). Smart Citizen Kit and Station: An open environmental monitoring system for citizen participation and scientific experimentation. HardwareX 6: e00070. doi: 10.1016/j.ohx.2019.e00070

Chan, C.Y., Xu, X.D., Li, Y.S., Wong, K.H., Ding, G.A., Chan, L.Y. and Cheng, X.H. (2005). Characteristics of vertical profiles and sources of $\mathrm{PM}_{2.5}, \mathrm{PM}_{10}$ and carbonaceous species in Beijing. Atmos. Environ. 39: 5113-5124. doi: 10.1016/j.atmosenv.2005.05.009

Cheng, Y., He, K.B., Du, Z.Y., Zheng, M., Duan, F.K. and Ma, Y.L. (2015). Humidity plays an important role in the $\mathrm{PM}_{2.5}$ pollution in Beijing. Environ. Pollut. 197: 68-75. doi: 10.1016/j.envpol.2014.11.028

Davidson, C.I., Phalen, R.F. and Solomon, P.A. (2005). Airborne particulate matter and human health: A review.
Aerosol Sci. Technol. 39: 737-749. doi: 10.1080/0278682 0500191348

Deng, X., Li, F., Li, Y., Li, J., Huang, H. and Liu, X. (2015). Vertical distribution characteristics of PM in the surface layer of Guangzhou. Particuology 20: 3-9. doi: 10.1016/j. partic.2014.02.009

Dickerson, R.R., Li, C., Li, Z., Marufu, L.T., Stehr, J.W., McClure, B., Krotkov, N., Chen, H., Wang, P., Xia, X. and Ban, X. (2007). Aircraft observations of dust and pollutants over northeast China: Insight into the meteorological mechanisms of transport. J. Geophys. Res. 112: D24S90. doi: 10.1029/2007JD008999

Ding, G., Chan, C., Gao, Z., Yao, W., Yoksheung, L.I., Cheng, X., Meng, Z., Yu, H., Wong, K., Wang, S. and Miao, Q. (2005). Vertical structures of $\mathrm{PM}_{10}$ and $\mathrm{PM}_{2.5}$ and their dynamical character in low atmosphere in Beijing urban areas. Sci. China Ser. D 48: 38-54.

Du, Y. and Rotunno, R. (2014a). A simple analytical model of the nocturnal low-level jet over the Great Plains of the United States. J. Atmos. Sci. 71: 3674-3683. doi: 10.1175/ JAS-D-14-0060.1

Du, Y., Zhang, Q., Chen, Y.L., Zhao, Y. and Wang, X. (2014b). Numerical simulations of spatial distributions and diurnal variations of low-level jets in China during early summer. J. Clim. 27: 5747-5767. doi: 10.1175/JCLID-13-00571.1

Fuzzi, S., Baltensperger, U., Carslaw, K., Decesari, S., Denier van der Gon, H., Facchini, M.C., Fowler, D., Koren, I., Langford, B., Lohmann, U. and Nemitz, E. (2015). Particulate matter, air quality and climate: Lessons learned and future needs. Atmos. Chem. Phys. 15: 8217-8299. doi: 10.5194/acp-15-8217-2015

Guo, J., Miao, Y., Zhang, Y., Liu, H., Li, Z., Zhang, W., He, J., Lou, M., Yan, Y., Bian, L. and Zhai, P. (2016). The climatology of planetary boundary layer height in China derived from radiosonde and reanalysis data. Atmos. Chem. Phys. 16: 13309-13319. doi: 10.5194/acp-16-13309-2016

Han, S., Liu, J., Hao, T., Zhang, Y., Li, P., Yang, J., Wang, Q., Cai, Z., Yao, Q., Zhang, M. and Wang, X. (2018). Boundary layer structure and scavenging effect during a typical winter haze-fog episode in a core city of BTH region, China. Atmos. Environ. 179: 187-200. doi: 10.1016/ j.atmosenv.2018.02.023

Hong, S.Y. (2010). A new stable boundary-layer mixing scheme and its impact on the simulated East Asian summer monsoon. Q. J. R. Meteorolog. Soc. 136: 14811496. doi: 10.1002/qj.665

Hu, J., Li, Y., Zhao, T., Liu, J., Hu, X.M., Liu, D., Jiang, Y., $\mathrm{Xu}$, J. and Chang, L. (2018). An important mechanism of regional $\mathrm{O}_{3}$ transport for summer smog over the Yangtze River Delta in eastern China. Atmos. Chem. Phys. 18: 16239-16251. doi: 10.5194/acp-18-16239-2018

Hu, X.-M., Klein, P.M., Xue, M., Zhang, F., Doughty, D.C., Forkel, R., Joseph, E. and Fuentes, J.D. (2013a). Impact of the vertical mixing induced by low-level jets on boundary layer ozone concentration. Atmos. Environ. 70: 123-130. doi: 10.1016/j.atmosenv.2012.12.046

Hu, X.-M., Klein, P.M., Xue, M., Lundquist, J.K., Zhang, F. and Qi, Y. (2013b). Impact of low-level jets on the 
nocturnal urban heat island intensity in Oklahoma City. $J$. Appl. Meteorol. Climatol. 52: 1779-1802. doi: 10.1175/J AMC-D-12-0256.1

Hu, X.-M., Ma, Z., Lin, W., Zhang, H., Hu, J., Wang, Y., $\mathrm{Xu}, \mathrm{X}$., Fuentes, J.D. and Xue, M. (2014). Impact of the Loess Plateau on the atmospheric boundary layer structure and air quality in the North China Plain: A case study. Sci. Total Environ. 499: 228-237. doi: 10.1016/j.sc itotenv.2014.08.053.

Huang, J., Wang, T., Wang, W., Li, Z. and Yan, H. (2014). Climate effects of dust aerosols over East Asian arid and semiarid regions. J. Geophys. Res. 119: 11398-11416. doi: 10.1002/2014JD021796

Jiang, J., Zhou, W., Cheng, Z., Wang, S., He, K. and Hao, J. (2015). Particulate matter distributions in China during a winter period with frequent pollution episodes (January 2013). Aerosol Air Qual. Res. 15: 494-503. doi: 10.4209/ aaqr.2014.04.0070

Kelly, K.E., Whitaker, J., Petty, A., Widmer, C., Dybwad, A., Sleeth, D., Martin, R. and Butterfield, A. (2017). Ambient and laboratory evaluation of a low-cost particulate matter sensor. Environ. Pollut. 221: 491-500. doi: 10.1016/j.envpol.2016.12.039

Kim, K.H., Kabir, E. and Kabir, S. (2015). A review on the human health impact of airborne particulate matter. Environ. Int. 74: 136-143. doi: 10.1016/j.envint.2014.10. 005

Kim, Y.J., Kim, K. W., Kim, S.D., Lee, B.K. and Han, J.S. (2006). Fine particulate matter characteristics and its impact on visibility impairment at two urban sites in Korea: Seoul and Incheon. Atmos. Environ. 40: 593-605. doi: 10.1016/j.atmosenv.2005.11.076

Klein, P.M., Hu, X.M. and Xue, M. (2014). Impacts of mixing processes in nocturnal atmospheric boundary layer on urban ozone concentrations. Boundary Layer Meteorol. 150: 107-130. doi: 10.1007/s10546-013-9864-4

Li, J., Li, C., Zhao, C. and Su, T. (2016). Changes in surface aerosol extinction trends over China during 1980-2013 inferred from quality-controlled visibility data. Geophys. Res. Lett. 43: 8713-8719. doi:10.1002/2016GL070201

Li, X., Ma, Y., Wang, Y., Liu, N. and Hong, Y. (2017). Temporal and spatial analyses of particulate matter $\left(\mathrm{PM}_{10}\right.$ and $\left.\mathrm{PM}_{2.5}\right)$ and its relationship with meteorological parameters over an urban city in northeast China. Atmos. Res. 198: 185-193. doi: 10.1016/j.atmosres.2017.08.023

Li, X., Wang, Y., Shen, L., Zhang, H., Zhao, H., Zhang, Y. and Ma, Y. (2018a). Characteristics of boundary layer structure during a persistent haze event in the central liaoning city cluster, northeast China. J. Meteorolog. Res. 32: 302-312. doi: 10.1007/s13351-018-7053-6

Li, X., Wang, Y., Zhao, H., Hong, Y., Liu, N. and Ma, Y. (2018b). Characteristics of pollutants and boundary layer structure during two haze events in summer and autumn 2014 in Shenyang, Northeast China. Aerosol Air Qual. Res. 18: 386-396. doi: 10.4209/aaqr.2017.03.0100

Li, X., Hu, X.M., Ma, Y., Wang, Y., Li, L. and Zhao, Z. (2019). Impact of planetary boundary layer structure on the formation and evolution of air-pollution episodes in Shenyang, Northeast China. Atmos. Environ. 214:
116850. doi: 10.1016/j.atmosenv.2019.116850

Li, Y., Chen, Q., Zhao, H., Wang, L. and Tao, R. (2015). Variations in $\mathrm{PM}_{10}, \mathrm{PM}_{2.5}$ and $\mathrm{PM}_{1.0}$ in an urban area of the Sichuan Basin and their relation to meteorological factors. Atmosphere 6: 150-163. doi: 10.3390/atmos6010150

Liu, Y., Tang, G., Zhou, L., Hu, B., Liu, B., Li, Y., Liu, S. and Wang, Y. (2019). Mixing layer transport flux of particulate matter in Beijing, China. Atmos. Chem. Phys. 19: 9531-9540. doi: 10.5194/acp-2019-141

Lu, S.J., Wang, D., Wang, Z., Li, B., Peng, Z.R., Li, X.B. and Gao, Y. (2019). Investigating the role of meteorological factors in the vertical variation in $\mathrm{PM}_{2.5}$ by unmanned aerial vehicle measurement. Aerosol Air Qual. Res. 19: 1493-1507. doi: 10.4209/aaqr.2018.07.0266

Ma, Y., Zhao, H., Dong, Y., Che, H., Li, X., Hong, Y., Li, X., Yang, H., Liu, Y., Wang, Y., Liu, N. and Sun, C. (2018). Comparison of two air pollution episodes over Northeast China in winter 2016/17 using ground-based lidar. $J$. Meteorolog. Res. 32: 313-323. doi: 10.1007/s13351-0187047-4

Masic, A., Pikula, B. and Bibic, D. (2017). Mobile measurements of particulate matter concentrations in urban area. Proceedings of the 28th DAAAM International Symposium, pp. 0452-0456, Katalinic, B. (Ed.), Published by DAAAM International, Vienna, Austria. doi: 10.2507/ 28th.daaam.proceedings.063

Miao, Y., Guo, J., Liu, S., Zhao, C., Li, X., Zhang, G., Wei, W. and Ma, Y. (2018). Impacts of synoptic condition and planetary boundary layer structure on the trans-boundary aerosol transport from Beijing-Tianjin-Hebei region to northeast China. Atmos. Environ. 181: 1-11. doi: 10.1016/j.atmosenv.2018.03.005

Miao, Y., Liu, S., Sheng, L., Huang, S. and Li, J. (2019). Influence of boundary layer structure and low-level jet on $\mathrm{PM}_{2.5}$ pollution in Beijing: A case study. Int. J. Environ. Res. Public Health 16: 616. doi: 10.3390/ijerph16040616 Myhre, G., Shindell, D., Breon, F.M., Collins, W., Fuglestvedt, J., Huang, J., Koch, D., Lamarque, J.F., Lee, D., Mendoza, B., Nakajima, T., Robock, A., Stephens, G., Takemura, T. and Zhang, H. (2013). Anthropogenic and natural radiative forcing. In Climate Change 2013: The Physical Science Basis. Contribution of Working Group I to the Fifth Assessment Report of the Intergovernmental Panel on Climate Change. Stocker, T.F., Qin, D., Plattner, G.K., Tignor, M., Allen, S.K., Boschung, J., Nauels, A., Xia, Y., Bex, V. and Midgley, P.M. (Eds.), Cambridge University Press, Cambridge, New York.

Nelson, K.N., Boehmler, J.M., Khlystov, A.Y., Moosmüller, H., Samburova, V., Bhattarai, C., Wilcox, E.M. and Watts, A.C. (2019). A multipollutant smoke emissions sensing and sampling instrument package for unmanned aircraft systems: development and testing. Fire 2: 32 . doi: 10.3390/fire2020032

Nielsen-Gammon, J.W., Powell, C.L., Mahoney, M.J., Angevine, W.M., Senff, C. and White, A. (2008). Multisensor estimation of mixing heights over a coastal city. J Appl. Meteorol. Climatol. 47: 27-43. doi: 10.1175/ 2007JAMC1503.1.

Oberdörster, G., Oberdörster, E. and Oberdörster, J. (2005). 
Nanotoxicology: An emerging discipline evolving from studies of ultrafine particles. Environ. Health Perspect. 113: 823-839. doi: 10.1289/ehp.7339

Sakhnini, N., Yu, J.E. and Chattopadhyay, D. (2018). myCityMeter: Helping older adults manage the environmental risk factors for cognitive impairment. Proceedings of the 2018 ACM International Joint Conference and 2018 International Symposium on Pervasive and Ubiquitous Computing and Wearable Computers, ACM, Singapore, Singapore, pp. 235-238.

Sayahi, T., Butterfield, A. and Kelly, K.E. (2019). Longterm field evaluation of the Plantower PMS low-cost particulate matter sensors. Environ. Pollut. 245: 932-940. doi: 10.1016/j.envpol.2018.11.065

Seidel, D.J., Zhang, Y., Beljaars, A., Golaz, J.C., Jacobson, A.R. and Medeiros, B. (2012). Climatology of the planetary boundary layer over the continental United States and Europe. J. Geophys. Res. 117: 1-15. doi: 10.1029/201 2JD018143.

Stull, R.B. (1988). Stable Boundary Layer, In An introduction to boundary layer meteorology, Stull, R.B. (Ed.), Springer Netherlands, Dordrecht, pp. 499-543.

Sun, Y., Song, T., Tang, G. and Wang, Y. (2013). The vertical distribution of $\mathrm{PM}_{2.5}$ and boundary-layer structure during summer haze in Beijing. Atmos. Environ. 74: 413421. doi: 10.1016/j.atmosenv.2013.03.011

Tang, G., Zhu, X., Hu, B., Xin, J., Wang, L., Münkel, C., Mao, G. and Wang, Y. (2015). Impact of emission controls on air quality in Beijing during APEC 2014: Lidar ceilometer observations. Atmos. Chem. Phys. 15: $12667-$ 12680, doi: 10.5194/acp-15-12667-2015

Tang, G., Zhang, J., Zhu, X., Song, T., Münkel, C., Hu, B., Schäfer, K., Liu, Z., Zhang, J., Wang, L., Xin, J., Suppan, P. and Wang, Y. (2016). Mixing layer height and its implications for air pollution over Beijing, China. Atmos. Chem. Phys. 16: 2459-2475. doi: 10.5194/acp-16-24592016

Tang, G., Zhao, P., Wang, Y., Gao, W., Cheng, M., Xin, J., Li, X. and Wang, Y. (2017). Mortality and air pollution in Beijing: The long-term relationship. Atmos. Environ. 150: 238-243. doi: 10.1016/j.atmosenv.2016.11.045.

Tiwari, S., Bisht, D.S., Srivastava, A.K., Pipal, A.S., Taneja, A., Srivastava, M.K. and Attri, S.D. (2014). Variability in atmospheric particulates and meteorological effects on their mass concentrations over Delhi, India. Atmos. Res. 145: 45-56. doi: 10.1016/j.atmosres.2014.03.027

Wang, L., Liu, J., Gao, Z., Li, Y., Huang, M., Fan, S., Zhang, X., Yang, Y., Miao, S., Zou, H. and Sun, Y. (2019). Vertical observations of the atmospheric boundary layer structure over Beijing urban area during air pollution episodes. Atmos. Chem. Phys. 19: 6949-6967. doi: 10.5194/ acp-19-6949-2019.

Wang, S.H., Welton, E.J., Holben, B.N., Tsay, S.C., Lin, N.H., Giles, D., Stewart, S.A., Janjai, S., Nguyen, X.A., Hsiao, T.C., Chen, W.N., Lin, T.H., Buntoung, S., Chantara, S. and Wiriya, W. (2015a). Vertical distribution and columnar optical properties of springtime biomass burning aerosols over northern Indochina during 2014 7-
SEAS Campaign. Aerosol Air Qual. Res. 15: 2037-2050. doi: 10.4209/aaqr.2015.05.0310

Wang, Y.Q., Zhang, X.Y., Sun, J.Y., Zhang, X.C., Che, H.Z. and Li, Y. (2015b). Spatial and temporal variations of the concentrations of $\mathrm{PM}_{10}, \mathrm{PM}_{2.5}$ and $\mathrm{PM}_{1}$ in China. Atmos. Chem. Phys. 15: 13585-13598. doi: 10.5194/acp-15-135852015

Wei, W., Zhang, H., Wu, B., Huang, Y., Cai, X., Song, Y. and $\mathrm{Li}, \mathrm{J}$. (2018). Intermittent turbulence contributes to vertical dispersion of $\mathrm{PM}_{2.5}$ in the North China Plain: cases from Tianjin. Atmos. Chem. Phys. 18: 12953-12967. doi: 10.5194/acp-18-12953-2018

Yang, W., Wang, G. and Bi, C. (2017). Analysis of longrange transport effects on $\mathrm{PM}_{2.5}$ during a short severe haze in Beijing, China. Aerosol Air Qual. Res. 17: 1510-1522. doi: 10.4209/aaqr.2016.06.0220

Yang, Y., Hu, X.M., Gao, S. and Wang, Y. (2019). Sensitivity of WRF simulations with the YSU PBL scheme to the lowest model level height for a sea fog event over the Yellow Sea. Atmos. Res. 215: 253-267. doi: 10.1016/j.atmosres.2018.09.004.

Zhang, H., Wang, Y., Hu, J. and Hu, X.M. (2015). Relationships between meteorological parameters and criteria air pollutants in three megacities in China. Environ. Res. 140: 242-254. doi: 10.1016/j.envres.2015.04.004

Zhang, K., Wang, D., Bian, Q., Duan, Y., Zhao, M., Fei, D., Xiu, G. and Fu, Q. (2017). Tethered balloon-based particle number concentration, and size distribution vertical profiles within the lower troposphere of Shanghai. Atmos. Environ. 154: 141-150. doi: 10.1016/j.atmosenv.2017.01.025

Zhao, H., Che, H., Zhang, X., Ma, Y., Wang, Y., Wang, H. and Wang, Y. (2013). Characteristics of visibility and particulate matter (PM) in an urban area of Northeast China. Atmos. Pollut. Res. 4: 427-434. doi: 10.5094/APR.2013.049

Zheng, T., Bergin, M.H., Johnson, K.K., Tripathi, S.N., Shirodkar, S., Landis, M.S., Sutaria, R. and Carlson, D.E. (2018). Field evaluation of low-cost particulate matter sensors in high-and low-concentration environments. Atmos. Meas. Tech. 11: 4823-4846. doi: 10.5194/amt-114823-2018

Zhu, X. Tang, G., Hu, B., Wang, L., Xin, J., Zhang, J., Liu, Z., Munkel, C. and Wang, Y. (2016). Regional pollution and its formation mechanism over North China Plain: A case study with ceilometer observations and model simulations. J. Geophys. Res. 121: 14574-14588. doi: 10.1002/2016JD025730

Zhu, X., Tang, G., Guo, J., Hu, B., Song, T., Wang, L., Xin, J., Gao, W., Münkel, C., Schäfer, K., Li, X. and Wang, Y. (2018). Mixing layer height on the North China Plain and meteorological evidence of serious air pollution in southern Hebei. Atmos. Chem. Phys. 18: 4897-4910. doi: 10.5194/acp-18-4897-2018

Received for review, June 19, 2019 Revised, October 3, 2019 Accepted, October 3, 2019 